Society is Dr. A. Nightingale, Physics Laboratory, St. Thomas's Hospital, London, S.E.I.

\section{Milk Hygiene}

THE second report of the Expert Committee on Milk Hygiene, set up jointly by the Food and Agriculture Organization and the World Health Organization, amplifies and supplements an earlier one published in 1957 (W.H.O. Technical Report Series, No. 197. Pp. 55. (Geneva: World Health Organization.) 2 Swiss francs ; 0.60 dollars. Also obtainable from H.M. Stationery Office. 3s. $6 d$. net. 1960). It deals first with some of the diseases that can be transmitted through milk, and refers especially to staphylococcal and streptococcal infoctions, and to tick-borne encephalitis. The nature of pasteurization and other forms of heat treatment, and their importance in reducing the danger of infection from milk itself and from milk products such as butter, cheese, fermented milk, dried milk and ice cream, are discussed. The fact is stressed that if in many countries of the world milk quality is to be significantly improved, information and exhortation about hygiene will not be enough; they will have to be accompanied by some system of payment for quality. A later section of the report describes some of the problems associated with dairying in warm countries, whore the standard of nutrition is frequently very low and where dairy products are very badly needed to improve the diets of the vast populations that live there. Reference is made to the production of milk in these areas not only from cows but also from buffaloes, goats and sheep. The report contains two annexes. One is a code of principles for milk and milk products prepared under the auspices of the Food and Agriculture Organization. The other contains a deseription of some twenty of the less-well-known milk products such as 'yogurt' and 'ghee' which are much used in parts of Europe and Asia. The report should be of particular value in those areas of the world where more dairy products are urgently required, but where, for various reasons, the production of milk and its products is still somewhat primitive and relatively little is known of the science of dairy technology.

\section{The Night Sky in December}

FULI moon occurs on Dec. 3d. 04h. 25m. U.T., and new moon on Dec. 18d. 10h. $47 \mathrm{~m}$. The following conjunctions with the Moon tako place: Dec. 3d. 0lh., Aldebaran 0.5 S.; Dec. 6d. 06h., Mars $7^{\circ}$ N. ; Dec. 21d. 15h., Venus $4^{\circ}$ S.; Dec. 30d. 07h., Aldebaran $0.4^{\circ} \mathrm{S}$. In addition to these conjunctions with the Moon, Mercury is in conjunction with Antares on Dec. $13 \mathrm{~d} .08 \mathrm{~m}$., Mercury being $5^{\circ} \mathrm{N}$. Mercury is a morning star, but conditions are not favourable for observation. Venus is an evening star, and conditions for observation are becoming favourable. Venus sets at $18 \mathrm{~h} .30 \mathrm{~m} ., 19 \mathrm{~h} .10 \mathrm{~m}$. and $19 \mathrm{~h} .55 \mathrm{~m}$. on December 1,15 and 31 , respectively, almost four hours after tho Sun on the latter date. During the month its distance from the Earth decreases from 102 to 83 million miles, the visible portion of the apparent disk from 0.744 to 0.639 , and its stellar magnitude from $-3 \cdot 6$ to $-3 \cdot 8$. Vonus is visible in the south-west after sunset. Mars rises at $18 \mathrm{~h} .05 \mathrm{~m}$. and $16 \mathrm{~h} .50 \mathrm{~m}$. on December 1 and 15, respectively, and is above the horizon at sunset on December 31 . It is retrograding in Gemini, and is at opposition on December 31 . Mars is closest to the Earth on December 25, when its distanee is 56 million miles and its stellar magnitude $-1 \cdot 3$. Mars is a very prominent object and ean be şen all night. Jupiter and Saturn set shortly after the Sun, and are unfavourably situated for observation. Occultations brighter than magnitude 6 are as follows, observations being made at Greenwich: Dec. 3d. 0h. 57.2m., $\propto$ Tau. $(D)$; Doc. 3d. 2h. $16 \cdot 3 \mathrm{~m} ., \propto$ Tau. $(R)$; Dec. 7 d. $3 \mathrm{~h} .53 \cdot 8 \mathrm{~m} ., 5$ Cnc. $(R)$; Dec. 10d. 3h. 25.7m., 44 Leo. $(R)$; Dec. 29 d. 23h. $43 \cdot 4 \mathrm{~m}$., $\gamma$ Tau. $(D)$. $D$ and $R$ refer to disappearance and reappearance, respectively. The Geminid meteors are active during December 9-14, but conditions for observation are unfavourable. The Ursids are active during December 20-22, and conditions are favourable; the radiant is near R.A. 14h. $28 \mathrm{~m}$., Dec. $+76^{\circ}$. The winter solstice occurs on Dec. 21 d. $20 \mathrm{~h}$.

\section{Announcements}

AT the recent Inter-American Course of Physiopathology of Roproduction and Artificial Insemination it was decided to form a Latin-American Association for Animal Fertility. The following were elected officers of the Association: Permanent Honorary President, Prof. T. Bonadonna (Milan); President, Prof. A. Hernandez Prado (Venezuela). It is expected that sections in the different South American. Republics will be established.

DR. M. R. Pollock, of the National Institute for Medical Research, London, will give the second Rapkine Memorial Lecture on "La Sécrétion d'enzymes par les Bactéries" at 5.30 p.m. on December 2 at the Laboratoire d'Evolution des Etres Organises, 105 Boulevard Raspail, Paris.

A MeEtivg on "Theoretical Rheology" is being organized by the British Society of Rheology at Reading during April 20-21, 1961. Further information can be obtained from Dr. M. F. Culpin, 8 The Broadway, Pontypool, Mon.

The National Institute of Agricultural Botany is holding a Crop Conference at its headquarters in Cambridge during December 13-14. Further information can be obtained from the Assistant Director, National Institute of Agricultural Botany, Huntingdon Road, Cambridge.

THE eighth annual Western Spectroscopy Conference will be held at Asilomar, Pacific Grove, California, during January 26-27, 1961. Further information can be obtained from the chairman of the Western Spectroscopy Association, Roland C. Hawes, Applied Physics Corporation, 2724 South Peck Road, Monrovia, California.

THE fifth conference on "Carbon" is to bo held at Pennsylvania State University during June 19-23, 1961. The conference is being sponsored by the American Carbon Committes and the Pennsylvania State University. Further information can be obtained from the chairman of tho Executive Committee, S. Mrozowski, American Carbon Committee, Carbon Research Laboratory, University of Buffalo, Buffalo 14, New York.

A symposium on "Large Capacity Memory Techniques for Computing Systems" will be held during May 23-25, 1961, at the Department of Interior Auditorium on $C$ Street, botween 18th and 19th Streets, N.W., Washington, D.C. The symposium is sponsored by the Information Systems Branch, Office of Naval Research. Further information can be obtained from Miss Josephine Leno, Code 430A, Office of Naval Research, Washington 25, D.C. 